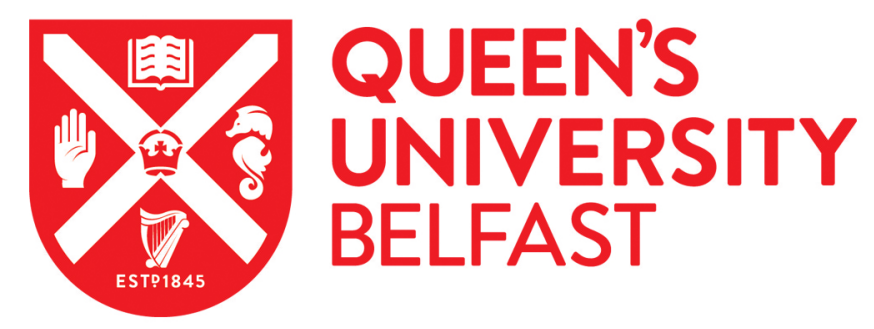

\title{
Does equality legislation reduce intergroup differences? Religious affiliation, socio-economic status and mortality in Scotland and Northern Ireland: a cohort study of 400,000 people
}

Wright, D. M., Rosato, M., Raab, G., Dibben, C., Boyle, P., \& O'Reilly, D. (2017). Does equality legislation reduce intergroup differences? Religious affiliation, socio-economic status and mortality in Scotland and Northern Ireland: a cohort study of 400,000 people. Health and Place, 32-38.

https://doi.org/10.1016/j.healthplace.2017.02.009

Published in:

Health and Place

Document Version:

Peer reviewed version

Queen's University Belfast - Research Portal:

Link to publication record in Queen's University Belfast Research Portal

\section{Publisher rights}

(c) 2017 Elsevier Ltd. This manuscript version is made available under the CC-BY-NC-ND 4.0 license http://creativecommons.org/licenses/bync-nd/4.0/, which permits distribution and reproduction for non-commercial purposes, provided the author and source are cited.

\section{General rights}

Copyright for the publications made accessible via the Queen's University Belfast Research Portal is retained by the author(s) and / or other copyright owners and it is a condition of accessing these publications that users recognise and abide by the legal requirements associated with these rights.

Take down policy

The Research Portal is Queen's institutional repository that provides access to Queen's research output. Every effort has been made to ensure that content in the Research Portal does not infringe any person's rights, or applicable UK laws. If you discover content in the

Research Portal that you believe breaches copyright or violates any law, please contact openaccess@qub.ac.uk. 
1 Does equality legislation reduce intergroup differences?

2 Religious affiliation, socio-economic status and mortality in

3 Scotland and Northern Ireland: a cohort study of 400,000 4 people.

5 David M. Wright ${ }^{1}$, Michael Rosato ${ }^{2}$, Gillian Raab ${ }^{3}$, Chris Dibben $^{3}$, Paul Boyle ${ }^{4}$, Dermot O’Reilly ${ }^{1}$

$6 \quad{ }^{1}$ Centre for Public Health, Queen's University Belfast, Belfast, UK

$7 \quad{ }^{2}$ Bamford Centre for Mental Health and Wellbeing, University of Ulster, Derry, UK

$8 \quad{ }^{3}$ University of Edinburgh, Edinburgh, UK

$9 \quad{ }^{4}$ University of Leicester, Leicester, UK

10 Corresponding Author: David Wright, Centre for Public Health, Institute of Clinical Sciences, Block B,

11 Queen's University Belfast, Royal Victoria Hospital, Grosvenor Road, Belfast, BT12 6BA UK.

12 d.wright@qub.ac.uk

Tel: (+44) 2890978939 
15

16

17

\section{Abstract}

Religion frequently indicates membership of socio-ethnic groups with distinct health behaviours and mortality risk. Determining the extent to which interactions between groups contribute to variation in mortality is often challenging. We compared socio-economic status (SES) and mortality rates of Protestants and Catholics in Scotland and Northern Ireland, regions in which interactions between groups are profoundly different. Crucially, strong equality legislation has been in place for much longer and Catholics form a larger minority in Northern Ireland. Drawing linked Census returns and mortality records of 404,703 people from the Scottish and Northern Ireland Longitudinal Studies, we used Poisson regression to compare religious groups, estimating mortality rates and incidence rate ratios. We fitted age-adjusted and fully adjusted (for education, housing tenure, car access and social class) models. Catholics had lower SES than Protestants in both countries; the differential was larger in Scotland for education, housing tenure and car access but not social class. In Scotland, Catholics had increased age-adjusted mortality risk relative to Protestants but variation among groups was attenuated following adjustment for SES. Those reporting no religious affiliation were at similar mortality risk to Protestants. In Northern Ireland, there was no mortality differential between Catholics and Protestants either before or after adjustment. Men reporting no religious affiliation were at increased mortality risk but this differential was not evident among women. In Scotland, Catholics remained at greater socio-economic disadvantage relative to Protestants than in Northern Ireland and were also at a mortality disadvantage. This may be due to a lack of explicit equality legislation that has decreased inequality by religion in Northern Ireland during recent decades.

Keywords: UK; mortality; equality legislation; religion; socio-economic status. 


\section{Introduction}

There is strong evidence that religion influences mortality risk through several mechanisms, including by the direct effects of spirituality on health and also by means of shared social capital, values and health behaviours of coreligionists (Sullivan, 2010). Religious involvement and practice has been associated with increased life expectancy (Hummer et al., 1999; McCullough et al., 2000) and variation in mortality rates among religions has been widely reported which is not completely explained by underlying variation in socio-economic status (SES) (Räsänen et al., 1996; O'Reilly and Rosato, 2008; Lerch et al., 2010). Mortality differences have also been found among denominations of the same religion that share a broad ethnic grouping. For example, there is significant variation in mortality among Christian denominations in Northern Ireland, with some conservative Protestant groups having reduced risk of alcohol and lung-cancer related deaths as a result of abstinence from alcohol and tobacco (O'Reilly and Rosato, 2008). Variation among religions extends to the experience of health conditions; some denominations report poorer health than others at a given level of clinical need (O'Reilly and Rosato, 2010) and there are interactions between the protective effects of religiosity and denomination (Sullivan, 2010). The balance between direct and indirect effects of religion on health varies and in some contexts religious affiliation acts primarily as an indicator of underlying sociological, cultural and ethnic identities and health behaviours, rather than as an indicator of religious practice (Field, 2014).

Interactions between religious groups may also influence health outcomes regardless of whether affiliation indicates practice or simply group membership, most notably where there is violent conflict (Pedersen, 2002). In less extreme cases where tensions exist between groups it is difficult to untangle the relative influences of group characteristics and between group interactions. For example, migrant groups may face discrimination and difficulty assimilating into settled populations potentially leading to stress and mental health problems (Levecque and Van Rossem, 2015) but these may be offset by greater resilience and better physical health among those prepared to move (Lu and Qin, 2014). To further complicate matters, exposure to intergroup tensions is likely to vary with the distribution of minority and majority groups and there is evidence that health outcomes worsen with increasing dispersion of minority groups among the majority (Bosqui et al., 2014). Associations between group density and health have been investigated extensively in terms of ethnicity (Bécares et al., 2012) but similar mechanisms are likely to apply for other group indicators including religious affiliation.

Assessing the balance between intra- and intergroup influences could make a valuable contribution towards targeting of interventions to improve population health. Here we describe an experiment of 
history and geography comparing mortality rates in two regions of the UK, Scotland and Northern Ireland, sharing the same major religious groups but in which interactions between the groups are profoundly different. Religious affiliation and practice have played major roles in the cultural development of both regions and whilst practice has waned in recent decades, affiliation remains a strong indicator of socio-cultural identity. Geographical proximity has led to frequent mixing of these populations; Scotland is historically strongly Protestant, but with a substantial and somewhat localised Catholic minority (16\% of the population at the 2011 Census) descended from mass Irish immigration during the 19th century (Williams, 1994). In recent decades levels of religious affiliation among Protestants have declined sharply and a large proportion of the population describe themselves as having no religion (Raab and Holligan, 2012). In Northern Ireland a large proportion of the Protestant population is descended from Scottish migrants who moved as part of the planned colonisation (Plantation) of Ulster during the 17th Century. Following the partition of Ireland in 1921, Catholics formed a minority in Northern Ireland that has increased in subsequent decades (Catholics formed $45 \%$ of the population at the 2011 Census).

In both regions there is a long history of tension along Protestant/Catholic lines, the recent manifestations of which differ. In Northern Ireland, civil unrest partly fuelled by discrimination against Catholics escalated into a violent sectarian conflict ('The Troubles') that lasted from 1969 for almost 30 years and in which over 3600 people were killed and many more wounded (Morrissey et al., 1999). Throughout this period several pieces of legislation were introduced to promote equality; the Fair Employment (Northern Ireland) Acts $(1976,1989)$ required employers to adopt fair recruitment and employment practices and regularly report the composition of the workforce by religion. These were superseded by the Fair Employment and Treatment Order (1998 - FETO) that also prohibited discrimination in the provision of goods and service. Following the Good Friday peace agreement of 1998 the Northern Ireland Act was introduced, requiring public bodies to explicitly consider the impact of new policies on equality (Section 75). Composition of the workforce changed over these decades to more closely match the mix of Protestants and Catholics available for work but inequalities in provision of social housing (covered by other legislation) were not reduced to the same extent (Russell, 2012; Cunningham, 2015) and residential segregation of Protestants and Catholics remained widespread (Boal, 2002; Lloyd and Shuttleworth, 2012; Shuttleworth et al., 2013; Doherty and Poole, 1997). In Scotland, although widespread violent conflict has been avoided, debate regarding the prevalence of sectarianism prompted the late introduction of religion questions to the 2001 Census. It has been suggested that prejudice against the minority Catholic population in the employment market has restricted upward social mobility, leading to higher levels of health problems associated with economic deprivation (Walls and Williams, 2004; Walls and 
Williams, 2003). Equality legislation of the type seen in Northern Ireland was not enacted in Scotland or the rest of Great Britain until the Equality Act of 2010 and there remains no analogue to the FETO. In neither region have the longer term impacts of equality legislation on population health been assessed.

We aimed to assess the relative influence of interactions between and characteristics of religious groups on health, quantifying variation in SES and mortality rates in Scotland and Northern Ireland by religion. In doing so we informally tested the hypothesis that equality legislation has been beneficial in terms of reducing health inequalities between denominations in Northern Ireland. There is evidence that Catholics in both Scotland and Northern Ireland have greater mortality risk than non-Catholics, largely explained by lower SES (O'Reilly and Rosato, 2008; Millard et al., 2015) but we expected that the differentials between groups in both SES and mortality risk would be larger in Scotland. We addressed the following research questions: a) Is there evidence Catholics are more disadvantaged relative to Protestants in Scotland than in Northern Ireland? b) Are there differences in mortality risk among religious groups in Scotland and Northern Ireland? c) To what extent might these be explained by differences in SES between groups?

\section{Methods}

\section{Data sources}

The Scottish Longitudinal Study (SLS) and Northern Ireland Longitudinal Study (NILS) are prospective record-linkage studies, derived from health card registrations and Census returns to which vital event data (births, marriages and deaths) have been linked. The SLS and NILS contain $5.3 \%$ and $28 \%$ samples of the respective populations (approximately 274,000 members in Scotland and 500,000 in Northern Ireland) and began with the 1991 and 1981 Censuses respectively. Details of the SLS, NILS and linkage processes are described elsewhere (O'Reilly et al., 2012; O'Reilly et al., 2008; Boyle et al., 2009). SLS and NILS data are held in secure environments at the General Register Office for Scotland (GROS) and Northern Ireland Statistics and Research Agency (NISRA) and the use of these data were approved by the ethics committees of the School of Geography and Geosciences, University of St. Andrews and the Office for Research Ethics Northern Ireland respectively.

\section{Characteristics of the cohort}

The cohort consisted of 156,448 people from the SLS and 248,255 people from the NILS, aged between 25 and 74 at the 2001 Census. The follow-up period lasted 6 years 8 months and the cohort experienced a total of 15,955 deaths during follow-up. People living in communal establishments and those reporting a non-Christian religion (1.6\% in Scotland and $0.4 \%$ in $\mathrm{NI}$ ) were excluded. 
In addition to age and sex we selected covariates from Census returns that have previously been associated with variation in mortality risk. Four indicators of socio-economic status were included. Social class was derived using the National Statistics Socio-economic Classification (NS-SEC)(Rose and Pevalin, 2002) of occupations to create seven categories (professional, intermediate, small employers/self-employed, lower supervisory, semi-routine/routine, never worked/long term unemployed, full-time student). A six category classification of educational attainment was used (university degree or equivalent, foundation degree/HNC, A-level/Higher, GCSE/Standard grade/OGrade, no recorded qualifications) along with three categories describing household car access (no access, one car, two or more).Finally, three categories of household tenure were defined (owner occupied, social rented, other).

Current religious affiliation was ascertained using the relevant census questions. The list of response options differed between Scotland and Northern Ireland so responses were classified into four main groups: Roman Catholic, Protestant, people reporting no religion and those that did not respond to the questions. In Northern Ireland, there was a two part question on current religious affiliation. Respondents were first asked if they belonged to any particular religion; those responding negatively constituted the 'no religion' analysis category. Those reporting an affiliation were asked what religion, denomination or body they were affiliated with. Respondents could choose from a list of four major Christian denominations (Roman Catholic, Presbyterian Church in Ireland, Church of Ireland, Methodist Church in Ireland) or specify 'Other' affiliation. For analysis purposes the three Protestant denominations were aggregated. In Scotland, a single question concerned current affiliation with the following response options: None, Church of Scotland, Roman Catholic, Other Christian, Buddhist, Hindu, Jewish, Muslim, Sikh, Another Religion. The Church of Scotland and 'Other Christian' groups were aggregated as Protestant for the analysis. Those from all non-Christian religions were considered to have 'Other' affiliation. In both countries, the small number of individuals reporting 'Other' affiliation (NILS = 769; SLS $=2551$ ) were excluded from the cohort prior to analysis.

\section{Analysis strategy}

The primary outcome measure was all-cause mortality during follow-up. We estimated mortality rates using Poisson regression models with person-years as the offset to obtain incidence rate ratios (IRRs) and 95\% confidence intervals (Cls) comparing those with different religious affiliation, adjusting first for age (using five year age classes) and then for both age and all measured covariates. We fitted separate models for each sex because preliminary analysis revealed interactions between 
these individuals at the age of 75 because beyond this age responses to the NS-SEC and educational attainment Census questions are not required.

A key feature of this study is the use of 'eDatashield' methodology to jointly analyse the two longitudinal studies at the individual level without individual level data being released from either of the secure settings (Wolfson et al., 2010). Relevant census questions were selected from each dataset and variables harmonised to ensure that factor levels were equivalent across both (e.g. matching Scottish and Northern Irish educational qualifications). Models were then fitted in the $R$ software environment ( $R$ Development Core Team, 2015) using specialist code which extracts the score and information matrix at each iteration of a Generalised Linear Model fitting process, combining them and returning them across and to all sites, repeating until model convergence. This is mathematically equivalent to an actual pooled analysis (Jones et al., 2012) which in the case of the NILS and SLS would be prohibited.

\section{Results}

Descriptive data from the populations by religion are given in Table 1. In Scotland, Catholics were socio-economically disadvantaged relative to Protestants, having lower levels of education, car and home ownership, although distribution of people among social classes (NS-SEC) was similar across religious groups. Those with no religious affiliation were at a slight advantage in terms of education compared with Protestants. Those who did not respond to the census question on religion had similar socio-economic characteristics to Catholics (Table 1).

In Northern Ireland Catholics were disadvantaged relative to Protestants with lower levels of home and car ownership and higher unemployment, despite similar educational achievement (Table 1). People reporting no religious affiliation were younger on average than Protestants or Catholics, were better educated (35\% with no qualifications compared with $48 \%$ for Catholics and Protestants) and were more likely to hold professional jobs, but were less likely to own homes. Those who did not respond to the census question had very similar characteristics to Catholics.

There were substantial differences in the overall SES profiles of Scotland and Northern Ireland. A smaller proportion were in the 'Professional' social class in Scotland than Northern Ireland but this was balanced by a larger proportion with routine occupations and much greater proportion of students. Overall, there was a more even distribution of people among social classes in Scotland than Northern Ireland. The proportion with the highest levels of education (degrees) was similar across both countries but Scotland had far fewer with no qualifications (a third vs. almost half in Northern Ireland). Levels of car access and house ownership were considerably lower in Scotland. 
There was greater variation between countries in SES profiles (for the two main groups combined) than between Catholics and Protestants within either country. For example, the difference between proportions with no qualifications in Scotland (30\%) and Northern Ireland (48\%) was larger than the difference between Catholics and Protestants in Scotland (34\% vs. $29 \%$ ) and Northern Ireland (no difference between groups). The differential between Catholics and Protestants (i.e. Catholic disadvantage) was larger in Scotland than Northern Ireland in terms of education, housing tenure and car access. The differential in terms of social class was less consistent, being similar across countries for most classes but notably larger in Northern Ireland for specific classes (e.g. unemployed, intermediate).

In fully-adjusted models including a religion by country interaction, mortality rates across both countries increased with deprivation across the majority of observed socio-economic factors (Table 2). For both sexes, car and home ownership were associated with decreased mortality risk. The relationships between educational qualifications, social class and mortality rates differed between sexes. Men with degrees had reduced mortality risk relative to all other groups and men with no qualifications were at greatest risk (IRR $=1.37[1.26,1.50])$. Women with no qualifications were at increased mortality risk relative to degree holders (IRR $=1.37[1.23,1.54])$ but risks for those with intermediate qualifications were similar to those for degree holders. Men with routine or lower supervisory jobs were at elevated mortality risk compared with those in the top three groups (professional, intermediate or small employers/self-employed) and unemployed men were at still greater risk. There were no significant differences in mortality risk among employed women but the unemployed or students were at increased risk.

Overall risk of mortality was higher in Scotland than Northern Ireland for both sexes (fully-adjusted models without a religion by country interaction; Table 3). There was greater variation among denominations in age-adjusted mortality rates for men in Scotland than in Northern Ireland (e.g. IRR ranges for men: 0.96, 1.39 in Scotland; 1.00, 1.21 in Northern Ireland; Table 3). There were similar levels of variation among women in age-adjusted mortality rates in both countries. In Scotland, Catholic men had an estimated 39\% higher risk of mortality than Protestant men, not adjusting for socio-economic status (Table 3 ). The differential was reduced to $14 \%$ in fully adjusted models. Among women the same pattern was observed although the age- and fully-adjusted excesses were only $29 \%$ and $12 \%$ respectively. In Northern Ireland there were no significant differences between Catholics and Protestants in age- or fully adjusted models for either men or women.

In Scotland, both men and women reporting no religious affiliation had similar mortality risks to Protestants. People who did not respond to the Census question were at greater risk than 
Protestants although this effect disappeared for women following adjustment for socio-economic status (Table 3). In Northern Ireland, men but not women reporting no religious affiliation were at greater risk than Protestants. Men who did not respond to the Census question had similar risks to Protestants but women who did not respond were at substantially greater risk (Table 3).

\section{Discussion}

We found considerable variation by religious affiliation in age-adjusted mortality rates and SES that was potentially driven by interactions among groups. The socio-economic differential between Catholics and Protestants was greater in Scotland (e.g. double the percentage difference in house ownership compared with Northern Ireland) as was the differential in age-adjusted mortality rates, especially among men. One explanation for this inequality is sectarian conflict which is most overt in relation to provision of Catholic schools and among fans of rival sports clubs (Bradley, 2006; Flint, 2012). More profoundly, lower socio-economic status and concomitant health problems among Scottish Catholics relative to Protestants have been attributed to discriminatory employment practices and latent sectarianism (Walls and Williams, 2003; Walls and Williams, 2004). Other authors dispute the importance of sectarianism in modern Scotland and suggestions that it contributes to the Scottish effect (excess mortality in Scotland in comparison with other regions of the UK that is not entirely explained by socio-economic status (SES) at either the individual or area level (Popham and Boyle, 2011)) have received little support (Graham et al., 2012). In our study Scottish Catholics had higher rates of unemployment than all other groups, consistent with our hypothesis that Catholic disadvantage would be more pronounced in Scotland due to the historical lack of explicit legislation banning discrimination by religion. Furthermore, legal protection may be of greater importance in Scotland due to the smaller relative size of the minority group (Catholics constituted $16 \%$ and $38 \%$ of the sample in Scotland and Northern Ireland respectively). Individuals in smaller minority groups are potentially exposed to a greater number of negative encounters with members of the majority group, although the spatial distribution of the respective communities is also likely to influence exposure (White and Borrell, 2011). These factors might also explain the differing patterns of SES-adjusted mortality rates across countries; Scottish Catholics were at elevated risk relative to Protestants but in Northern Ireland there was no such differential.

We found little evidence that religious affiliation contributed additional mortality risk above that explained by SES, instead finding considerable variation within groups between sexes and countries. The majority of this variation was explained by socio-economic factors, indicating that the main religious groups in Scotland and Northern Ireland have similar lifestyles and health behaviours at given levels of deprivation. A previous study in Northern Ireland found that Catholics had similar 
risks of mortality in comparison with all other groups combined (including those with no religion) but that some Protestant groups, notably more conservative denominations were at reduced risk when considered separately (O'Reilly and Rosato, 2008). These beneficial health outcomes were attributed to the negative attitudes of these groups to alcohol and tobacco. Similarly, a recent Scottish study reported differentials in social class and deprivation between those raised in the Church of Scotland and 'other Christians' (Millard et al., 2015), differences that were reflected in mortality rates (least deprived and lowest mortality for 'other Christians'). A limitation of our study was that by aggregating across Protestant denominations we were unable to explore these effects.

An alternative explanation for the socio-economic and mortality disadvantages for Scottish Catholics is that as many are descended from Irish immigrants who arrived in the 1840s, there has been insufficient time to overcome the socio-economic disadvantages faced by migrant relative to established populations (Abbotts et al., 1997; Williams, 1994). In Britain, successive generations claiming Irish Catholic ethnicity have experienced gradual improvements in health outcomes but inequalities with the rest of the population persist (Abbotts et al., 1997; Raab and Holligan, 2012). The health inequalities faced by the Irish diaspora in England are still detectable in the second and third generation post-immigration even though socio-economic inequalities have decreased (DasMunshi et al., 2013; S Harding et al., 1996; S Harding and R Balarajan, 2001). Regardless of the causal pathway, Catholics in Scotland remain disadvantaged relative to Protestants in both socio-economic and health terms and so it might be beneficial to explore policies aiming to redress this imbalance, perhaps seeking inspiration from Northern Ireland where interdenominational differences in socioeconomic status have been reduced in recent years (Todd and Ruane, 2011).

The degree of excess mortality that we found among Scottish men relative to Northern Irish men was consistent with that in a comparison of mortality rates in Belfast and Glasgow (Graham et al., 2012) but we found considerably greater excess risk among Scottish women than was found among women in Glasgow. Although Scottish Catholics remained at slightly higher mortality risk than Protestants when socio-economic conditions were accounted for, religious affiliation is unlikely to be a major contributor to the Scottish effect because Catholics constituted just $16 \%$ of the sample and the majority Protestant group were also at elevated risk compared with their Northern Irish counterparts.

Protestants and Catholics combined formed the vast majority of the study populations $(70 \%$ and $87 \%$ in Scotland and Northern Ireland respectively) but a third group, those reporting no current religious affiliation constituted a quarter of the sample from Scotland. This group is increasingly important; the proportion of the Scottish population describing themselves as belonging to no 
religion has increased over recent years and is largely formed of younger people with a Protestant heritage (Raab and Holligan, 2012). In our cohort this group was at a slight advantage in terms of education compared with Protestants, reflecting the relative youth of the 'no religion' group. Those in Scotland with no religion had similar mortality risks to Scottish Protestants and so our comparisons along Protestant/Catholic lines are unlikely to have altered if this group of 'exProtestants' was included. In Northern Ireland also, the 'no religion' group was slightly younger and more highly educated in comparison with Protestants and Catholics. There was some indication that among men mortality risks were higher for those with no religion but given the relatively small size of the 'no religion' group and that the association was not evident among women, strong conclusions should not be drawn from this result. The 'no religion' group was proportionally much smaller in Northern and Ireland than in Scotland and the fact that a larger proportion of the Northern Ireland population reported either Protestant or Catholic affiliation suggests that these markers of political and national identity retain greater importance in the more openly divided political space of Northern Ireland than in Scotland.

In Scotland, those that did not respond to the Census questions on religious affiliation had similar SES and mortality risks to Catholics. In Northern Ireland the similarities between the Catholic and non-respondent groups were less clear; SES of both sexes and mortality risks for men were very similar between groups but estimated mortality risks for women appeared higher for nonrespondents than Catholics (although this contrast was not statistically significant given the low nonresponse rate). These findings indicate that Catholics formed the majority of non-respondents in both regions perhaps due to distrust of government institutions. It is notable that non-response rates were similarly low in both countries, despite the fact that in Scotland response to the Census religion question was voluntary whereas in Northern Ireland responses were compulsory.

Religious affiliation and ethnicity are closely interlinked in both Scotland and Northern Ireland. The majority of people who identify themselves as 'white Irish' in Scotland are Catholic (Office of the Chief Statistician, 2004). Similarly Presbyterians, one of the major Protestant groups in Northern Ireland share strong historical and ethnic links to successive waves of Scottish immigration, the largest of which began during the 17th century (Whan, 2013). Despite these ties, our analysis of mortality risks by current religion augments recent studies of interethnic variation in Scotland. Our finding that Catholic men were at increased risk of mortality relative to Protestants was not reflected in comparisons of health outcomes between white Irish and white Scottish people. There were no significant differences in incidence rates for chest pain, angina, heart failure, stroke and several cancers between these two groups (Bhopal et al., 2012b; Bhopal et al., 2012a; Bhopal et al., 2012c; 
334 Fischbacher et al., 2007). Therefore, current religious affiliation appears to provide additional information to ethnicity when investigating health outcomes in Scotland.

336 We used a novel method (eDatashield) to simultaneously analyse individual-level data from both 337 datasets without sharing sensitive data between countries, enabling us to make direct comparisons 338 of the patterns present in each country. This approach brings advantages in terms of statistical 339 power over traditional meta-analysis of data from multiple sites. Despite this strength, in common 340 with many longitudinal studies of health determinants, there remains the potential for confounding 341 by unobserved variables. The measures of socio-economic status that we selected are all recognised 342 predictors of mortality but important health-related variables including alcohol consumption or 343 smoking status were not included in the census questionnaires. As linkages between administrative, 344 health and census data become more common the scope for controlling for and investigating these 345 effects should widen.

346 A limitation of this study was that we restricted analysis to people for whom the full range of SES 347 information was available, thus excluding those aged 75 and over. It is possible that this age group 348 may exhibit a different pattern of mortality differentials between Protestants and Catholics as a 349 result of changes in the relationships between the groups over time. In Northern Ireland, older 350 cohorts were potentially exposed to greater sectarian tension prior to the peace agreements and so 351 might exhibit differentials in mortality not seen among the younger cohorts. An interesting line of future work would be to investigate this potential cohort effect and to determine whether mortality differentials have changed over time in Scotland. Data from additional Censuses have recently been added to both the SLS and NILS which now extend for 20 and 30 years respectively and which would now render such an analysis possible.

356 In conclusion, we have shown that mortality differentials among religious groups are not consistent 357 across Scotland and Northern Ireland, countries where religious affiliation has historically been an important cultural identifier. In Scotland, Catholics remain at a greater socio-economic disadvantage relative to Protestants than in Northern Ireland and are also at mortality disadvantage. These disadvantages may result from sectarian discrimination acting on a much smaller minority group that is without the protection of the well- established anti-discrimination legislation enacted in Northern Ireland. 


\section{References}

364 Abbotts, J., Williams, R., Ford, G., Hunt, K., West, P., 1997. Morbidity and Irish Catholic descent in Britain: An ethnic and religious minority 150 years on. Social science \& medicine 45, 3-14.

Bécares, L., Shaw, R., Nazroo, J., Stafford, M., Albor, C., Atkin, K., Kiernan, K., Wilkinson, R., Pickett, Review of the Literature. Am J Public Health 102, e33-e66.

Bhopal, R.S., Bansal, N., Fischbacher, C., Brown, H., Capewell, S., (on behalf of the Scottish Health and Ethnicity Linkage Study (SHELS)), 2012a. Ethnic variations in chest pain and angina in men and women: Scottish Ethnicity and Health Linkage Study of 4.65 million people. European Journal of Preventive Cardiology 19, 1250-1257.

Bhopal, R.S., Bansal, N., Steiner, M., Brewster, D.H., on behalf of the Scottish Health and Ethnicity Linkage Study, 2012b. Does the 'Scottish effect' apply to all ethnic groups? All-cancer, lung, colorectal, breast and prostate cancer in the Scottish Health and Ethnicity Linkage Cohort Study. BMJ Open 2. Ethnic Linkage Study), 2012c. Ethnic variations in the incidence and mortality of stroke in the Scottish Health and Ethnicity Linkage Study of 4.65 million people. European Journal of Preventive Cardiology 19, 1503-1508.

Boal, F.W., 2002. Belfast: walls within. Political Geography 21, 687-694. effect in psychotic disorders. Social psychiatry and psychiatric epidemiology 49, 519-529. 
Bradley, J.M., 2006. Sport and the Contestation of Ethnic Identity: Football and Irishness in Scotland. Journal of Ethnic and Migration Studies 32, 1189-1208.

Cunningham, T., 2015. Monitoring equality - reflexive regulation, planning systems, and the role of 389 discrimination law: lessons from Northern Ireland. The Equal Rights Review 14, 119-247.

Das-Munshi, J., Clark, C., Dewey, M.E., Leavey, G., Stansfeld, S.A., Prince, M.J., 2013. Does childhood adversity account for poorer mental and physical health in second-generation Irish people living in Britain? Birth cohort study from Britain (NCDS). BMJ Open 3.

Doherty, P., Poole, M.A., 1997. Ethnic residential segregation in Belfast, Northern Ireland, 19711991. Geographical Review 87, 520-536.

Field, C.D., 2014. Measuring religious affiliation in Great Britain: the 2011 census in historical and methodological context. Religion 44, 357-382.

Fischbacher, C., Steiner, M., Bhopal, R., Chalmers, J., Jamieson, J., Knowles, D., Povey, C., 2007. Variations in all Cause and Cardiovascular Mortality by Country of Birth in Scotland, 1997-2003. Scottish medical journal 52, 5-10.

Flint, J., 2012. Catholic Schools and Sectarianism in Scotland: Educational Places and the Production and Negotiation of Urban Space. Policy Futures in Education 10, 507-517. deprivation compare in Glasgow and Belfast? Public health 126, 378-385. 

mortality. Demography 36, 273-285.

406

407

408

409

410

411

412

413

414

415

416

417

418

419

420

421

422

423

Jones, E.M., Sheehan, N.A., Masca, N., Wallace, S.E., Murtagh, M.J., Burton, P.R., 2012. DataSHIELD -

a shared individual-level analysis without sharing the data: a biostatistical perspective. Norsk epidemiologi 21, 231-239.

Lerch, M., Oris, M., Wanner, P., Forney, Y., 2010. Religious affiliation and mortality in Switzerland, 1991-2004. Population 65, 217-250.

Levecque, K., Van Rossem, R., 2015. Depression in Europe: does migrant integration have mental health payoffs? A cross-national comparison of 20 European countries. Ethnicity \& health 20, 49-65.

Lloyd, C.D., Shuttleworth, I., 2012. Residential segregation in Northern Ireland in 2001: assessing the value of exploring spatial variations. Environment and Planning A 44, 52-67.

Lu, Y., Qin, L., 2014. Healthy migrant and salmon bias hypotheses: A study of health and internal migration in China. Social science \& medicine 102, 41-48.

McCullough, M.E., Hoyt, W.T., Larson, D.B., Koenig, H.G., Thoresen, C., 2000. Religious involvement and mortality: A meta-analytic review. Health Psychology 19, 211-222.

Millard, A.D., Raab, G., Lewsey, J., Eaglesham, P., Craig, P., Ralston, K., McCartney, G., 2015. Mortality differences and inequalities within and between 'protected characteristics' groups, in a Scottish Cohort 1991-2009. International Journal for Equity in Health 14, 142.

Morrissey, M., Fay, M., Smyth, M., 1999. Northern Ireland's Troubles : The Human Costs. Pluto Press, London, GBR. 
424 O'Reilly, D., Rosato, M., 2010. Dissonances in self-reported health and mortality across 425 denominational groups in Northern Ireland. Social science \& medicine 71, 1011-1017.

426 O’Reilly, D., Rosato, M., Catney, G., Johnston, F., Brolly, M., 2012. Cohort description: The Northern 427 Ireland Longitudinal Study (NILS). International journal of epidemiology 41, 634-641.

Office of the Chief Statistician. 2004Analysis of Ethnicity in the 2001 Census - Summary reportScottish ExecutiveEdinburgh.

430 O'Reilly, D., Rosato, M., 2008. Religious affiliation and mortality in Northern Ireland: Beyond Catholic 431 and Protestant. Social science \& medicine 66, 1637-1645.

O'Reilly, D., Rosato, M., Connolly, S., 2008. Unlinked vital events in census-based longitudinal studies can bias subsequent analysis. Journal of clinical epidemiology 61, 380-385.

Pedersen, D., 2002. Political violence, ethnic conflict, and contemporary wars: broad implications for health and social well-being. Social science \& medicine 55, 175-190.

Popham, F., Boyle, P.J., 2011. Is there a 'Scottish effect' for mortality? Prospective observational 437 study of census linkage studies. Journal of Public Health 33, 453-458.

R Development Core Team, 2015. R: A Language and Environment for Statistical Computing. R Foundation for Statistical Computing, Vienna, Austria.

Raab, G., Holligan, C., 2012. Sectarianism: myth or social reality? Inter-sectarian partnerships in 441 Scotland, evidence from the Scottish Longitudinal Study. Ethnic and Racial Studies 35, 1934-1954.

442 Rose, D., Pevalin, D., 2002. A Researcher's Guide to the National Statistics Socio- Economic 443 Classification. Sage, London. 
444 Raymond T. Russell. 2012Fair employment in Northern Ireland: the decades of change (1990 445 2010)Northern Ireland Assembly Research and Information ServiceBelfast.

446 Räsänen, J., Kauhanen, J., Lakka, T.A., Kaplan, G.A., Salonen, J.T., 1996. Religious Affiliation and All447 Cause Mortality: A Prospective Population Study in Middle-Aged Men in Eastern Finland. International journal of epidemiology 25, 1244-1249.

S Harding, R Balarajan, 2001. Mortality of third generation Irish people living in England and Wales:

450 longitudinal study. BMJ 322, 466-467.

S Harding, R Balarajan, R Balarajan, 1996. Patterns of mortality in second generation Irish living in England and Wales: longitudinal study. BMJ 312, 1389-1392.

Shuttleworth, I., Barr, P.J., Gould, M., 2013. Does Internal Migration in Northern Ireland Increase 2001-2007. Population, Space and Place 19, 72-86. Attendance. Journal for the scientific study of religion 49, 740-753. Action and Equality Measures on Conflict in Northern Ireland. Debating Affirmative Action.

Walls, P., Williams, R., 2004. Accounting for Irish Catholic ill health in Scotland: a qualitative exploration of some links between religion, class and health. Sociology of health \& illness $26,527-$ 556. Irish Catholics in Scotland. Ethnic and Racial Studies 26, 632-661. 
White, K., Borrell, L.N., 2011. Racial/ethnic residential segregation: Framing the context of health risk and health disparities. Health \& place 17, 438-448.

Wolfson, M., Wallace, S.E., Masca, N., Rowe, G., Sheehan, N.A., Ferretti, V., LaFlamme, P., Tobin, M.D., Macleod, J., Little, J., Fortier, I., Knoppers, B.M., Burton, P.R., 2010. DataSHIELD: resolving a conflict in contemporary bioscience--performing a pooled analysis of individual-level data without sharing the data. International journal of epidemiology 39, 1372-1382.

\section{Acknowledgements}

476 This study was funded as part of the UK Centre of Excellence for Public Health, Northern Ireland 477 initiative (grant number MR/K023241/1).

478 The help provided by the staff of the Northern Ireland Longitudinal Study (NILS) and the NILS 479 Research Support Unit is acknowledged. The NILS is funded by the Health and Social Care Research 480 and Development Division of the Public Health Agency (HSC R\&D Division) and NISRA. The NILS-RSU 481 is funded by the ESRC and the Northern Ireland Government. The authors alone are responsible for the interpretation of the data and any views or opinions presented are solely those of the author and do not necessarily represent those of NISRA/NILS.

The help provided by staff of the Longitudinal Studies Centre - Scotland (LSCS) is acknowledged. The LSCS is supported by the ESRC/JISC, the Scottish Funding Council, the Chief Scientist's Office and the Scottish Government. The authors alone are responsible for the interpretation of the data. Census output is Crown copyright and is reproduced with the permission of the Controller of HMSO and the 

variables. Sources: Scottish Longitudinal Study and Northern Ireland Longitudinal Study.

\begin{tabular}{|c|c|c|c|c|c|c|c|c|}
\hline & \multicolumn{4}{|c|}{ Scotland } & \multicolumn{4}{|c|}{ Northern Ireland } \\
\hline & Catholic & Protestant & No religion & $\begin{array}{c}\text { Not } \\
\text { answered }\end{array}$ & Catholic & Protestant & No religion & $\begin{array}{c}\text { Not } \\
\text { answered }\end{array}$ \\
\hline$N$ & 25366 & 84126 & 41083 & 5873 & 94393 & 122254 & 22659 & 8949 \\
\hline Age & 46.9 & 50.1 & 41.2 & 46.4 & 45.56 & 48.19 & 43.51 & 46.77 \\
\hline Total person years & 157116 & 511329 & 260491 & 36025 & 597325 & 759772 & 141742 & 55560 \\
\hline$\%$ men & 44.6 & 45.6 & 53.4 & 50.3 & 47.0 & 47.3 & 55.5 & 51.8 \\
\hline Intermediate & 15.2 & 15.7 & 15.2 & 13.5 & 9.7 & 13.2 & 11.9 & 13.6 \\
\hline Small employers/self employed & 10.3 & 12.5 & 12.5 & 10.6 & 10.9 & 10.3 & 9.2 & 8.8 \\
\hline Lower supervisory & 14.6 & 15.7 & 15.4 & 13.0 & 8.4 & 9.8 & 9.4 & 9.5 \\
\hline (Semi) routine & 24.7 & 22.5 & 23.3 & 27.7 & 34.9 & 33.5 & 27.6 & 29.7 \\
\hline \multicolumn{9}{|l|}{ Never worked/Long term } \\
\hline unemployed & 10.2 & 9.4 & 9.2 & 9.5 & 8.6 & 4.2 & 5.5 & 8.7 \\
\hline O grade/GCSEs & 24.4 & 24.6 & 23.6 & 23.9 & 16.0 & 16.7 & 17.3 & 16.0 \\
\hline Highers/2 + A-levels & 17.4 & 17.9 & 18.0 & 17.0 & 13.0 & 14.1 & 14.7 & 14.4 \\
\hline HNC/Foundation degree & 10.3 & 11.9 & 12.5 & 9.5 & 5.8 & 5.7 & 8.4 & 6.9 \\
\hline Degree & 14.2 & 16.7 & 17.8 & 16.8 & 17.0 & 15.3 & 25.2 & 17.3 \\
\hline
\end{tabular}


Car access

\begin{tabular}{|c|c|c|c|c|c|c|c|c|}
\hline None & 35.7 & 32.0 & 34.3 & 33.6 & 17.0 & 12.8 & 17.0 & 18.0 \\
\hline One & 40.3 & 39.6 & 39.9 & 40.4 & 44.9 & 42.5 & 44.4 & 45.6 \\
\hline Two or more & 24.0 & 28.4 & 25.8 & 25.9 & 38.1 & 44.7 & 38.6 & 36.4 \\
\hline \multicolumn{9}{|l|}{ Housing tenure } \\
\hline Owner occupied & 66.2 & 74.2 & 70.8 & 66.0 & 77.6 & 81.6 & 74.8 & 75.2 \\
\hline Social rented & 27.8 & 19.8 & 21.2 & 25.2 & 17.1 & 13.6 & 15.4 & 18.1 \\
\hline Other & 6.0 & 6.0 & 8.0 & 8.7 & 5.3 & 4.8 & 9.8 & 6.7 \\
\hline
\end{tabular}


494 Table 2. Relationship between socio-economic factors and all-cause mortality risk in Scotland and

495 Northern Ireland (IRRs and 95\% Cls). Models were fitted separately for each sex and adjusted for 496 age, housing tenure, social class, car access, education, religion and country. Corresponding religion 497 and country estimates are presented in Table 3. Sources: Scottish Longitudinal Study and Northern 498 Ireland Longitudinal Study.

\begin{tabular}{lll} 
& Men & Women \\
\hline Social class (NS-SEC) & & \\
Professional & 1.00 & 1.00 \\
Intermediate & $1.11(0.99,1.23)$ & $1.03(0.93,1.13)$ \\
Small employers/self employed & $1.05(0.97,1.14)$ & $0.88(0.75,1.04)$ \\
Lower supervisory & $1.21(1.12,1.31)$ & $0.90(0.78,1.03)$ \\
(Semi) routine & $1.13(1.05,1.21)$ & $1.06(0.97,1.15)$ \\
Never worked/Long term unemployed & $1.34(1.20,1.49)$ & $1.37(1.23,1.54)$ \\
Full-time student & $0.97(0.57,1.65)$ & $1.70(1.19,2.42)$ \\
& & \\
Education & & \\
No qualifications & $1.37(1.26,1.50)$ & $1.37(1.23,1.54)$ \\
O grade/GCSEs & $1.21(1.09,1.34)$ & $1.03(0.90,1.17)$ \\
Highers/2 + A-levels & $1.23(1.11,1.38)$ & $1.11(0.97,1.27)$ \\
HNC/Foundation degree & $1.18(1.02,1.37)$ & $1.11(0.91,1.35)$ \\
Degree & 1.00 & 1.00 \\
Car access & & \\
None & & $1.76(1.61,1.92)$ \\
One & $2.33(2.16,2.50)$ & $1.37(1.23,1.54)$ \\
Two or more & $1.35(1.27,1.43)$ & 1.00 \\
Housing tenure & 1.00 & 1.00 \\
Owner occupied & & $1.60(1.50,1.71)$ \\
Social rented & 1.00 & $1.37(1.23,1.53)$ \\
Other & $1.42(1.34,1.50)$ & \\
\hline
\end{tabular}


500 Table 3. All-cause mortality comparing religious groups in Scotland and Northern Ireland (IRRs and

$50195 \% \mathrm{Cls}$ ). Models fitted separately for each sex. *Adjusted for age, housing tenure, social class, car 502 access, education. Corresponding covariate estimates are presented in Table 2. **Overall 503 comparison of mortality rates in Scotland and Northern Ireland from models without religion by 504 country interactions. Sources: Scottish Longitudinal Study and Northern Ireland Longitudinal Study.

\begin{tabular}{|c|c|c|c|c|}
\hline & \multirow{2}{*}{$\begin{array}{c}\text { Men } \\
\text { Adjusted for age }\end{array}$} & \multicolumn{3}{|c|}{ Women } \\
\hline & & Fully adjusted* & Adjusted for age & Fully adjusted* \\
\hline \multicolumn{5}{|l|}{ Scotland } \\
\hline Protestant & 1.00 & 1.00 & 1.00 & 1.00 \\
\hline Catholic & $1.39(1.28,1.51)$ & $1.14(1.04,1.24)$ & $1.29(1.17,1.42)$ & $1.12(1.01,1.23)$ \\
\hline No religion & $0.96(0.88,1.05)$ & $0.95(0.88,1.04)$ & $1.01(0.90,1.13)$ & $0.96(0.86,1.08)$ \\
\hline Not answered & $1.32(1.13,1.54)$ & $1.20(1.02,1.40)$ & $1.35(1.12,1.63)$ & $1.19(0.99,1.43)$ \\
\hline \multicolumn{5}{|l|}{ Northern Ireland } \\
\hline Protestant & 1.00 & 1.00 & 1.00 & 1.00 \\
\hline Catholic & $1.05(0.99,1.12)$ & $0.95(0.89,1.02)$ & $1.07(0.99,1.15)$ & $0.99(0.91,1.07)$ \\
\hline No religion & $1.21(1.09,1.34)$ & $1.12(1.01,1.25)$ & $1.16(1.00,1.35)$ & $1.09(0.94,1.27)$ \\
\hline Not answered & $1.13(0.97,1.31)$ & $1.05(0.90,1.22)$ & $1.36(1.14,1.61)$ & $1.27(1.07,1.51)$ \\
\hline Scotland & & & & \\
\hline Northern Ireland** & & $1.19(1.14,1.25)$ & & $1.26(1.20,1.34)$ \\
\hline
\end{tabular}

